\title{
A STUDY OF ILIZAROV TECHNIQUE IN TREATMENT OF TIBIAL NON-UNIONS
}

\author{
Naresh Kumar'1, Mahendra Bendale² \\ ${ }^{1}$ Assistant Professor, Department of Orthopaedics, KMCT Medical College, Mukkam, Kerala. \\ ${ }^{2}$ Assistant Professor, Department of Orthopaedics, KMCT Medical College, Mukkam, Kerala.
}

ABSTRACT

\section{BACKGROUND}

The Ilizarov technique using circular external fixator depends on the principle of distraction histogenesis, which mimics the changes of normal bone growth. Since 1950 this technique provided an important new tool for the orthopaedic surgeon in the management of a variety of congenital and acquired bone problems. Its application in non-union of fractures helps through distraction, deangulation and compression. The distinct advantage of Ilizarov treatment is the active use of the limb to restore physiologic functions as the fixator supports the extremity and simultaneously allows the patients to work and be active. This study is conducted to report the results of this technique for treatment of non-union tibia at our institution.

Aims of this study is to assess the efficacy of the Ilizarov circular external ring fixator in the management of non-union of tibial fractures following failure in previous surgical attempts.

\section{MATERIALS AND METHODS}

30 patients with fractured tibia progressing to non-union were included in the study and treated with Ilizarov external fixator. The patients with non-union for more than 4 months were included, investigated and operated.

\section{RESULTS}

30 male patients with tibial non-unions were treated in our institute, 24 cases were infected and 2 were previously infected cases. The average number of previous failed surgical attempts at union was 1.3 procedure per patient (range 1 - 3 per patient). The average pre-operative duration of symptomatic non-union was 10 . Of the 30 patients, 21 patients with shortening associated with bone fragment contact, 4 patients with bone loss in excess of amount of shortening, 5 patients without shortening and bone loss (nonunion with less than $1 \mathrm{~cm}$ of bone loss); 21 of these patients were treated with compression of the non-union site and lengthening of the leg through a separate corticotomy site (bifocal treatment); 4 patients were treated by corticotomy and internal bone transport, 1 patient was treated by compression distraction at the non-union site and 2 patients were treated with compression alone and 2 patients were treated by stabilisation.

\section{CONCLUSION}

We obtained a union rate of $83.33 \%$ primarily, $90 \%$ patients obtained union with additional protection and minor procedures like bone grafting improved the union rate to $93.33 \%$. Control of infection occurred in $88.46 \%$ of cases. Ilizarov technique is a comprehensive method that addresses management of the bone defect, soft tissue loss and infection deformity and limb length discrepancy simultaneously. Control of infection and correction of limb length discrepancy can be more reliably achieved.

\section{KEYWORDS}

Fracture, Tibia, Non-Union, External Compression, Distraction and Ilizarov.

HOW TO CITE THIS ARTICLE: Kumar N, Bendale M. A study of ilizarov technique in treatment of tibial non-unions. J. Evolution Med. Dent. Sci. 2016;5(95):7009-7015, DOI: 10.14260/Jemds/2016/1585

\begin{tabular}{|c|c|}
\hline BACKGROUND & Wagner developed a simple monolateral fixator for limb \\
\hline $\begin{array}{l}\text { Management of non-union in fracture bones with external } \\
\text { applicators during the early } 19^{\text {th }} \text { century was described by } \\
\text { many authors, but none of them stood the test of time. In 1951, } \\
\text { Gavril Baranovichi Ilizarov with the concept of distraction } \\
\text { osteogenesis described his technique of external applicators in } \\
\text { the management of nonunion. }{ }^{1} \text { But it was not until 1981, the } \\
\text { knowledge of his technique was disseminated to the rest of the } \\
\text { world. Since then this "Ilizarov method" has become a } \\
\text { significant part of the Orthopaedic Surgeon's armamentarium. }\end{array}$ & $\begin{array}{l}\text { lengthening in } 1963 \text {, and used bone grafting and plating to fill } \\
\text { the distraction gap. }{ }^{2} \text { The AO unilateral frame compiled by } \\
\text { Weber and Cech came into vogue in } 1973 .{ }^{3} \text { De Bastiani well } \\
\text { aware of the principle drawbacks of the Hoffman, Wagner and } \\
\text { AO systems introduced the dynamic axial fixator in } 1979.4 \text { The } \\
\text { Ilizarov fixator was modified later by Marticilli Spinelli and } \\
\text { Ognasion in the eighties. }{ }^{5} \text { Fractures of the tibial diaphysis } \\
\text { treated with intra-medullary nailing, plating, casting, bracing } \\
\text { or external fixation may go on to delayed union or non-union }\end{array}$ \\
\hline $\begin{array}{l}\text { Financial or Other, Competing Interest: None. } \\
\text { Submission 21-10-2016, Peer Review 14-11-2016, } \\
\text { Acceptance 22-11-2016, Published 28-11-2016. } \\
\text { Corresponding Author: } \\
\text { Dr. Naresh Kumar, } \\
\text { Assistant Professor, } \\
\text { Department of Orthopaedics, } \\
\text { KMCT Medical College, Mukkam, Kerala. } \\
\text { E-mail: nareshbalussery@yahoo.co.in } \\
\text { DOI: } 10.14260 / \text { jemds/2016/1585 } \\
\text { (c) } 9 \text { (1) } \Theta\end{array}$ & $\begin{array}{l}\text { in } 10-30 \% \text { of cases. } 6,7,8 \text { Factors associated with an increased } \\
\text { risk of tibial non-union include comminution, segmental } \\
\text { defect, intact fibula, soft tissue injury, infection, multiple } \\
\text { trauma and delayed weight bearing. Difficult or recalcitrant } \\
\text { infection usually requires a more radical debridement of the } \\
\text { septic bone and soft tissue in addition to application of stable } \\
\text { fixation to enhance soft tissue healing and bony union. }{ }^{9} \\
\text { External fixator therefore in the environment of active } \\
\text { diaphyseal infection appears to be the standard treatment for } \\
\text { limb stabilisation. External fixator provides a minimal amount }\end{array}$ \\
\hline
\end{tabular}


of foreign body material in the perinonunion area and if properly constructed provides sufficient stability to the extremity. ${ }^{9}$ The present study was conducted to review the efficacy of the Ilizarov circular external ring fixator in the management of non-union of tibial fractures following failure in previous surgical attempts in a tertiary hospital setting.

\section{MATERIALS AND METHODS}

Institutional Ethical Committee clearance was taken for the study. Due consent from the patients was obtained in standard Proforma before commencing the treatment. All fractures included in this study were those, which showed no clinical or radiological evidence of union four months after the fracture. This minimum time period was taken arbitrarily with the realisation that some fracture of the tibial shaft, e.g. comminuted ones take more than four months to heal. Thirty cases of non-union of tibia treated by Ilizarov method were followed up at the KMCT Medical College Hospital, Mukkam during the period from December 2014 to September 2016.

\section{Inclusion Criteria}

1. Patients presenting with non-union of tibial fracture after 4 months.

2. Patients treated earlier with other surgeries like internal fixation.

3. Patients aged above 20 years.

\section{Exclusion Criteria}

1. Patients presenting with associated fractures in other long bones; 2 . Tibial fractures with non-union, less than 4 months; 3. Comminuted fractures of tibia. These cases were followed up for a minimum period of one year and maximum period of 30 months. Data regarding the patient like age, sex and side of injury, interval between the fracture and procedure for nonunion were obtained from the patient himself. Union of the fractures was evaluated in all patients examined by careful history, by clinical examination (pain on stressing the fracture, mobility at the fracture site and warmth of the overlying skin) and recent roentgenograms made in the antero-posterior and lateral projections. Discharging sinus, exposed bone and wound communicating with the fracture classified the nonunion as infected. Previous number of procedures was determined according to the modality of treatment and not depending on the number of operations done. The total amount of bone loss was the defect before application of the frame and included clinical shortening, radiological bone loss and the amount of bone excised during debridement if the fracture site was exposed. Eradication of infection was evaluated by the absence of discharging sinus, complete healing of wound. Functional status of the patient is assessed by following criteria. Invalid $\left(\mathrm{F}_{0}\right)$, able to perform activities of daily living $\left(F_{1}\right)$, complete recovery $\left(F_{2}\right)$.

\section{Ilizarov Technique}

Non-union with minimal shortening or without shortening was treated with either stabilisation, compression or compression followed by distraction at non-union site, and those with unacceptable shortening was treated with bone transport. A corticotomy was done to enhance healing of nonunion when the vascularity of the ends of the bones was questionable. Defects in the skin were allowed to granulate after which split skin grafting was done. Radiographs were carefully analysed before surgery and a decision was made regarding the removal of hardware, need for debridement, fibulectomy, corticotomy and opening the fracture site for excision of bone ends or opening of medullary canal. The size and number of rings used were then determined and a preassembly constructed positioning two rings above and two rings below the non-union site. If the non-union was along the metaphyseo-diaphyseal region of the bone, a single ring was used in the metaphysis with two rings in the distal fragments. The distance between the rings was confirmed radiologically and clinically whenever possible. Patient was positioned with the leg kept elevated with cushions allowing assess all around the limb. Wires were inserted through the safe corridors taking care to transfix as little soft tissue as possible; muscles were stretched to their full length, while transfixing them and the wires were pushed through the soft tissue without spinning motion to avoid neurovascular injury. Heating was prevented by continuously cooling the wires with saline. All wires were tensioned with a dynamometer. Alignment at the non-union was confirmed with image intensifier. Minor adjustments of angulations was corrected by compression on one side with distraction at the other, larger deformities were corrected with hinges. Compression of non-union by $5 \mathrm{~mm}$ was done and confirmed by bowing of the wires. Betadine soaked dressing were then applied. Dressing was changed daily and physiotherapy encouraged from $1^{\text {st }}$ post-operative day; patients were discharged; partial weight bearing on crutches after a few days of distraction. Patient and relatives were explained in which direction the nuts had to be turned after marking them. Rate of distraction was fixed at $1 \mathrm{~mm} /$ day in four divided increments. The rate was adjusted as required according to followup x-rays. Amount of distraction was adjusted depending on the bone loss. At follow-up if no signs of fixator instability was present, the patient was encouraged to bear more weight on the affected leg. Pin tract, range of motion of knee and ankle, rate at which union was progressing, appearance of axial deviation or other complications were noted. Quality of regenerate was carefully assessed. Fixator removal was done when the union was sound clinically and radiologically; corticalisation of regenerate indicated its maturity. After removal, patients were immobilised in a cast for variable periods depending on union characteristics.

\section{RESULTS}

Thirty patients aged 21 to 60 years were treated for tibial nonunions by the Ilizarov technique and fixator. Among them twenty five were atrophic and five were hypertrophic. Twenty six patients had infection, twenty five patients had limb length discrepancy $(1-9 \mathrm{~cm})$, four patients had bone defect and twenty five patients had shortening and two patients had deformity. Duration of non-union had ranged from 4 to 18 months and most patients had previous attempt at union with a mean of 1.3 procedures per patient (Range 1 - 3). Previous attempts include various procedures like external fixator application, bone grafting, plates and screws, intramedullary devices, Ilizarov ring fixator and myocutaneous flaps. The age distribution is shown in Table 1. Patients belonging to the age group of 25 to 44 years were amounting to $76.66 \%$. 


\begin{tabular}{|c|c|}
\hline Range of Age & Number of Patients \\
\hline $15-24$ & 2 \\
\hline $25-34$ & 12 \\
\hline $35-44$ & 11 \\
\hline $45-54$ & 4 \\
\hline $55-64$ & 1 \\
\hline \multicolumn{2}{|c|}{ Table 1. Showing the Age Distribution, $(\mathbf{n}=\mathbf{3 0})$} \\
\hline
\end{tabular}

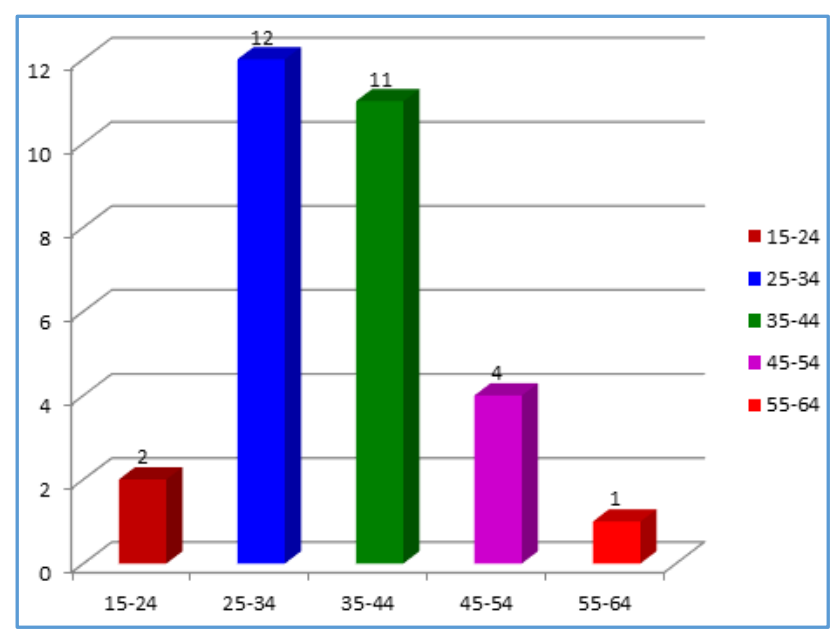

Figure 1. Showing the Age Distribution, $(n=30)$

12 patients presenting with Type - IIIB were included in the present study (40\%), 7 (23.33\%) were with type II and 5 (16.66\%) were with type - IIIC, (Table 2).

\begin{tabular}{|c|c|}
\hline Type of Fracture & Number of Patients \\
\hline Closed & 2 \\
\hline Type I & 1 \\
\hline Type II & 7 \\
\hline Type - IIIA & 3 \\
\hline Type - IIIB & 12 \\
\hline Type - IIIC & 5 \\
\hline Table 2. Showing the Types of Fractures \\
Included in the Study, (n=30)
\end{tabular}

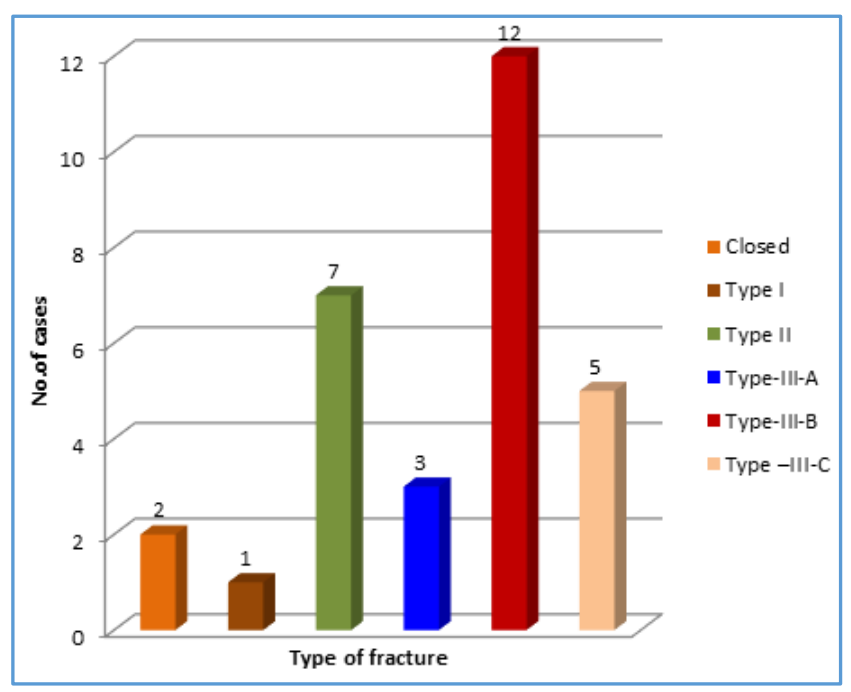

Figure 2. Showing the Types of Fractures Included in the Study, $(n=30)$
$43.33 \%$ of patients in the present were of atrophic type of non-union (Table 3).

\begin{tabular}{|c|c|c|}
\hline \multicolumn{2}{|c|}{ Type of Non-Union } & No. of Patients \\
\hline \multirow{3}{*}{ Hypertrophic type } & Elephant foot & 2 \\
\cline { 2 - 3 } & Horse hoof & 3 \\
\hline \multirow{3}{*}{ Atrophic type } & Atrophic & 13 \\
\cline { 2 - 3 } & Defect & 4 \\
\cline { 2 - 3 } & Comminuted & 6 \\
\cline { 2 - 3 } & Torsion wedge & 2 \\
\hline \multicolumn{2}{|c|}{ Table 3. Showing the Type of Non-Union, (n = 30) } \\
\hline
\end{tabular}

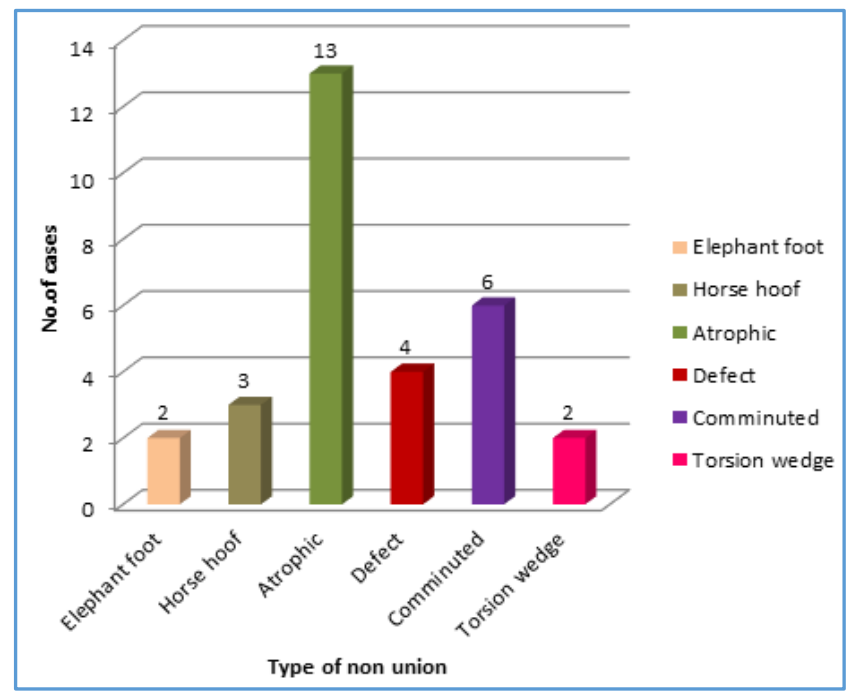

Figure 3. Showing the Type of Non-Union, $(n=30)$

History of Proforma of previous infection showed that 24 of them were infected (80\%), (Table 4).

\begin{tabular}{|c|c|}
\hline Status of Infection & Number of Cases \\
\hline Previously infected & 2 \\
\hline Infected & 24 \\
\hline Non-infected & 4 \\
\hline \multicolumn{2}{|c|}{$\begin{array}{c}\text { Table 4. Showing Proforma of Cases } \\
\text { with Respect to Infection, }(n=30)\end{array}$} \\
\hline
\end{tabular}

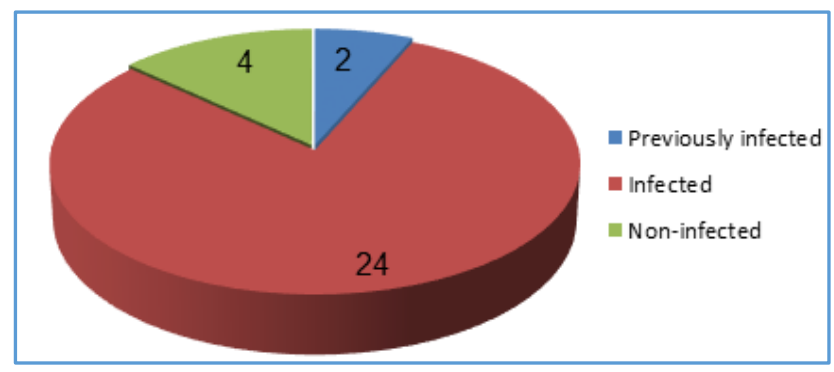

Figure 4. Showing Proforma of Cases with Respect to Infection, $(n=30)$

\begin{tabular}{|c|c|}
\hline $\begin{array}{c}\text { Range of Treatment Period in } \\
\text { Months }\end{array}$ & $\begin{array}{c}\text { Number of } \\
\text { Patients }\end{array}$ \\
\hline $5-9.9$ & 11 \\
\hline $10-14.9$ & 10 \\
\hline $15-19.9$ & 7 \\
\hline $20-24.9$ & 2 \\
\hline \multicolumn{2}{|c|}{ Table 5. Showing the Treatment Period, $(\mathbf{n}=\mathbf{3 0})$} \\
\hline
\end{tabular}




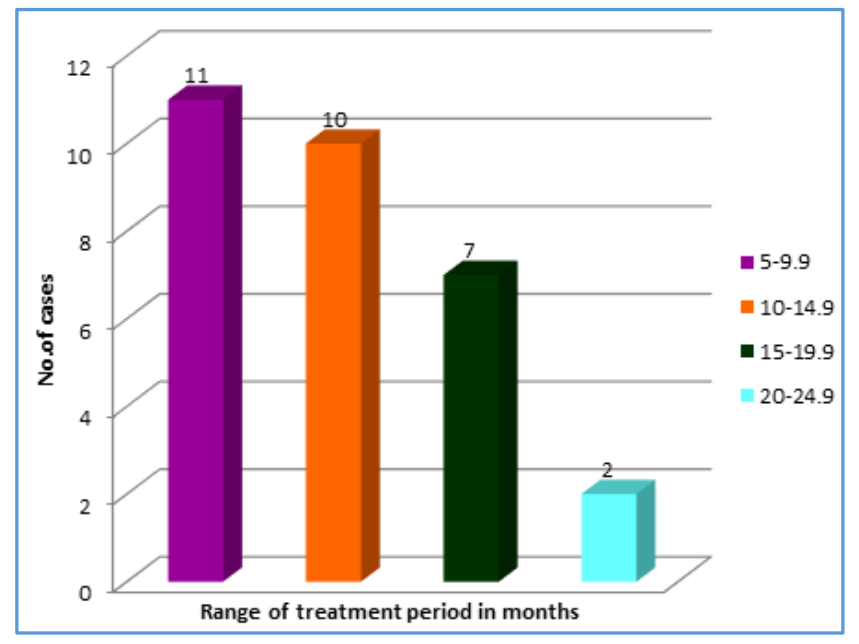

Figure 5. Showing the

Treatment Period, $(n=30)$

36.66 percent of our patients achieved a union in 5 - 9.9 months of treatment, $33.33 \%$ cases took 10 - 14.9 months, (Table 5).

The average time period in the fixator was 10.24 months (range 3 - 24 months), additional protection ranging from protected weight bearing with crutches to cast application were used. Total duration of treatment ranged from 5 months to 25 months.

Few patients required surgical intervention while in the fixator ranging from fixator readjustment, releasing skin around wire in pin tract infection, freshening the corticotomy and bone grafting. An average hospital stay of 50 days was required ranging from 30 to 105 days; all cases were followed up from 12 to 30 months. Of the 30 cases of non-unions treated with the device, 23 united primarily (76.66\%). There were two cases of re-fractures, which were treated with reapplication of the apparatus, corticotomy and compression of the non-union site. Both cases united after a period of 5 months, two cases required more than 4 months of additional protection as the union was not sound, but healed without any more intervention. Three patients required additional bone grafting, out of which one united. The remaining two fails to unite. Twenty three of the twenty six infected cases had no evidence of active infection on follow-up patients, continues to show draining sinuses. Twenty two of the twenty five extremities were equal or within $2.5 \mathrm{~cm}$ of length compared with the contralateral side. The overall average increase in length of the regenerated new bone formation was $2.46 \mathrm{~cm}$ (range 2 to 6 $\mathrm{cm})$. Two patients had angulations deformity of more than 70 in the coronal plane, which was corrected by the application of hinges. The clinical followup results were evaluated using three parameters; union, infection and function. Failure to obtain union was indicted by $\mathrm{U}_{0}$ and solid union by $\mathrm{U}_{1}$. Infection was evaluated by 10 for unchanged infection and $I_{1}$ for complete clinical remission of infection. Function was evaluated as $\mathrm{F}_{0}$ for invalid, $\mathrm{F}_{1}$ able to perform all activities of daily living and $F_{2}$ complete recovery. There were twenty five patients with rating of $\mathrm{U}_{1} 1_{1} \mathrm{~F}_{2}$ and were regarded as excellent, two patients received rating of $\mathrm{U}_{1} 1_{0} \mathrm{~F}_{2}$ and were rated as good. In one patient rating is $\mathrm{U}_{1} \mathrm{I}_{0} \mathrm{~F}_{0}$ and is considered fair and two patients which failed to show union $\mathrm{U}_{0} 1_{0} \mathrm{~F}_{0}$ was rated poor.
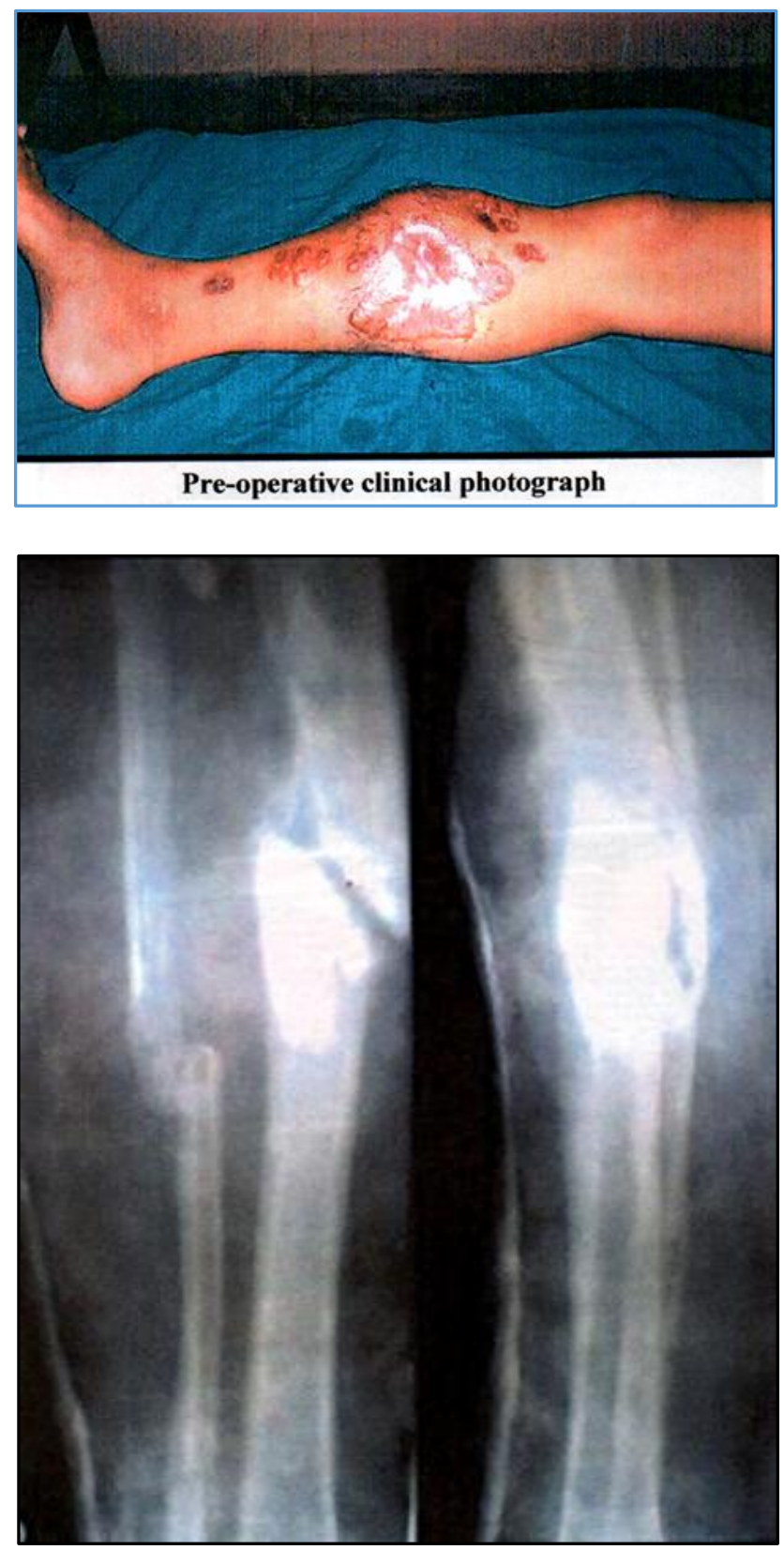

Pre-Operative - X-Ray

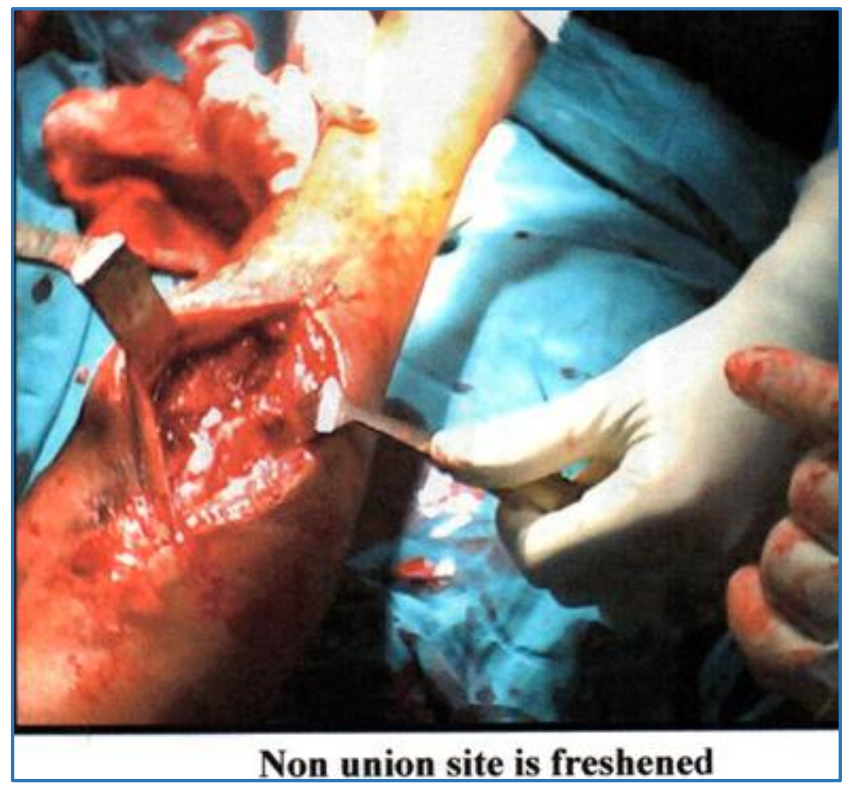



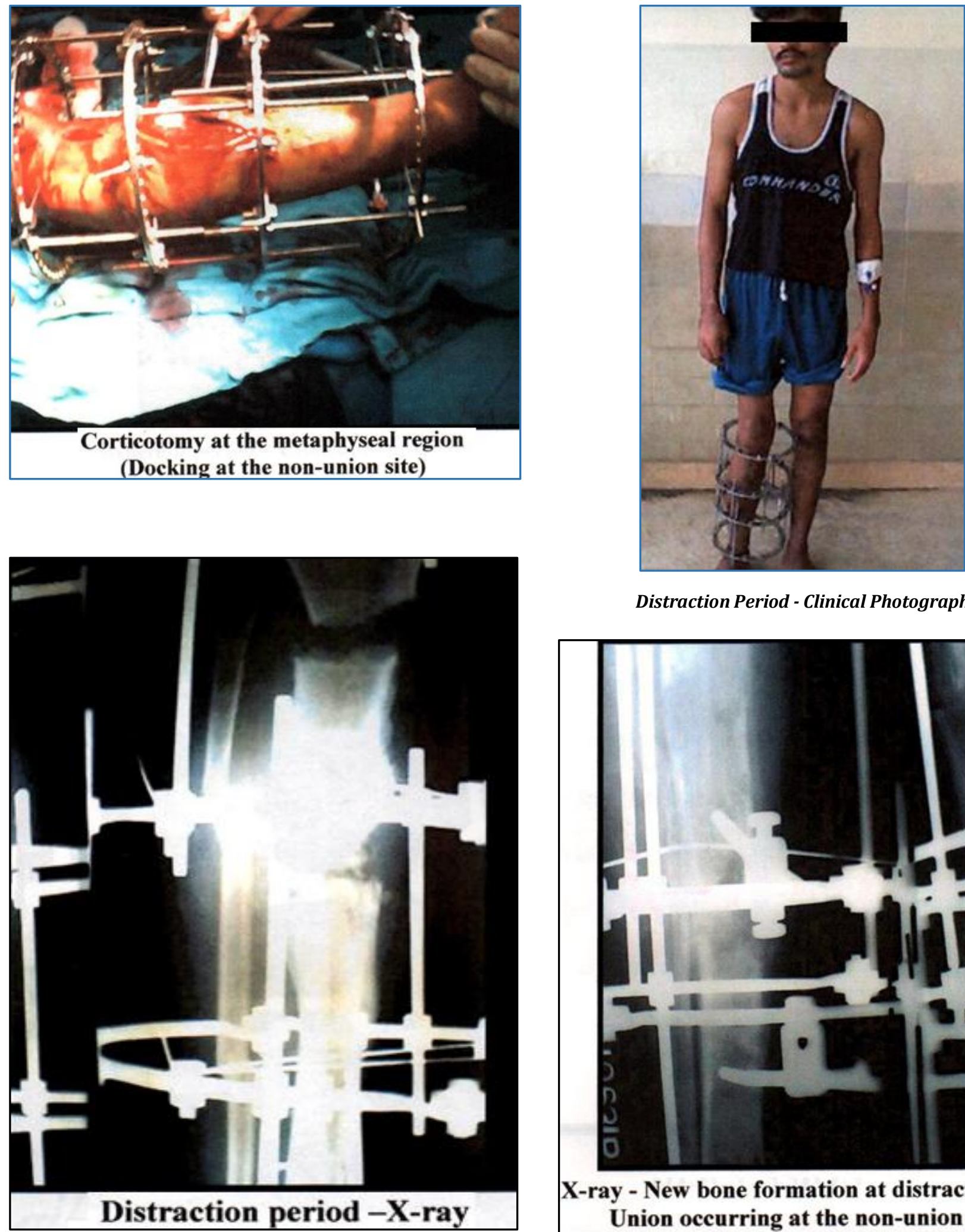

Distraction Period - Clinical Photograph

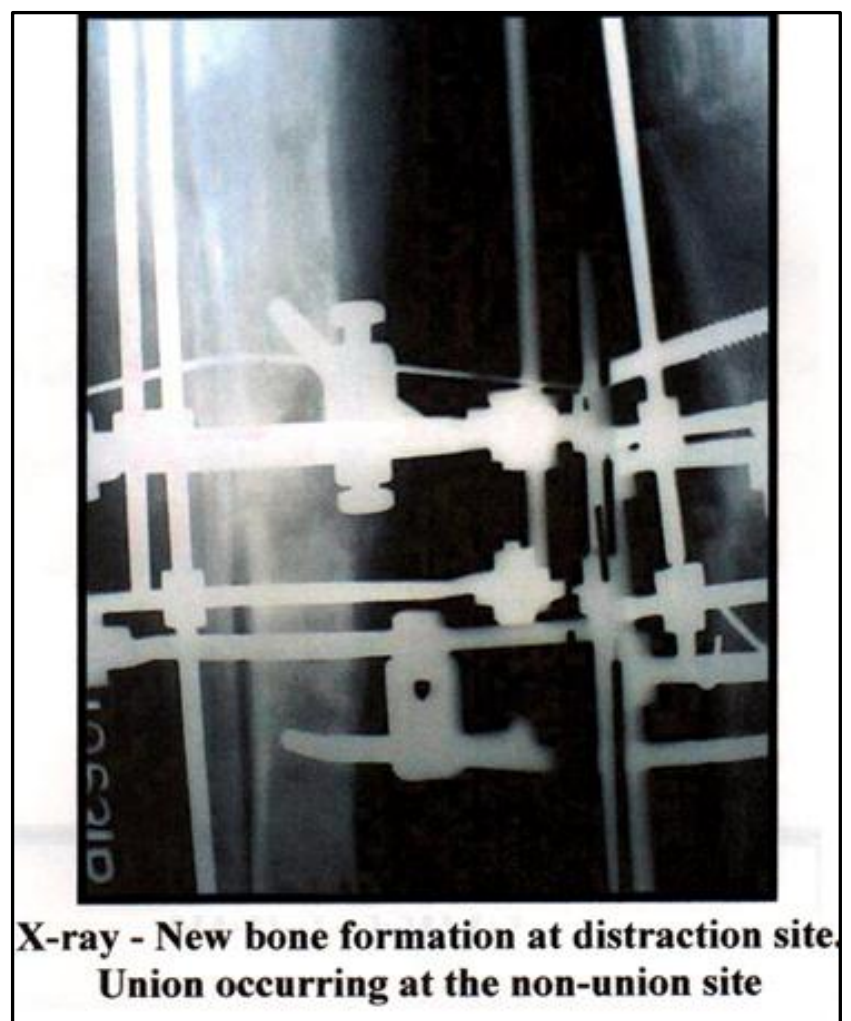




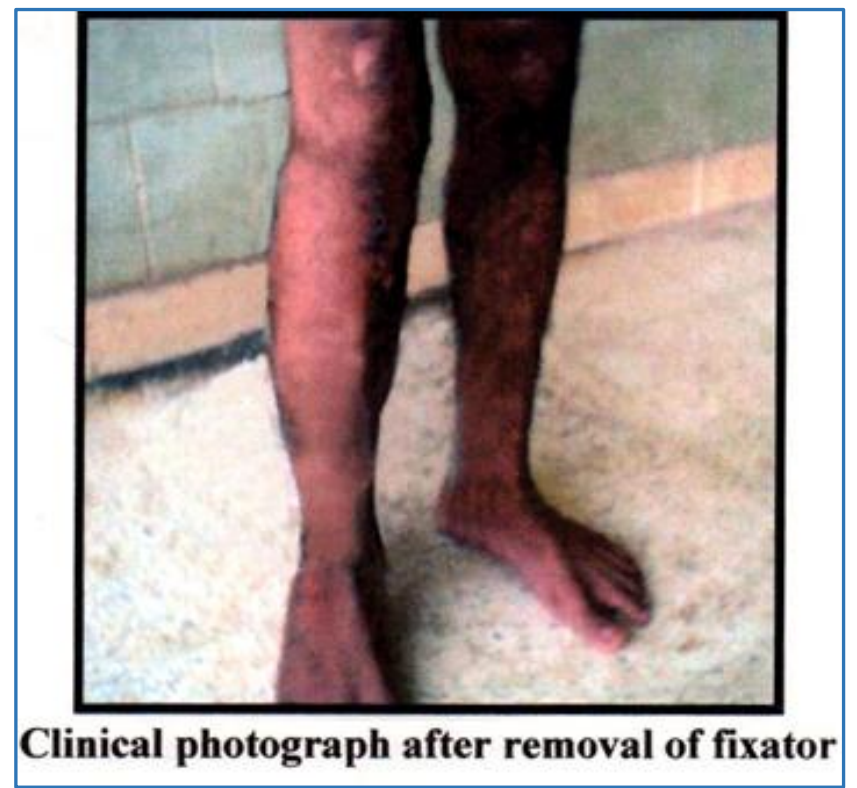

\section{DISCUSSION}

Tibial non-unions, a relatively frequent complication of tibial fractures presents a perplexing problem for orthopaedic surgeon, especially when combined with infection, deformity and bone loss. Therapy for non-union have varied from immobilisation in a cast to staged microvascular reconstruction, success rates have varied from $70-90 \%$ and many of the techniques requires the limb to be free from infection. The Ilizarov method is a comprehensive approach to all aspects of chronic tibial non-union that simultaneously addresses deformity, shortening, defects, infection, articular and limb function, weight bearing, osteoporosis and soft tissue atrophy. Control of infection was obtained by improving vascularity and by bold resection of infected bone and soft tissues. Limb length equalisation was carried out with bone transport. The bone thus formed was reliable, did not undergo volume loss with time, had little donor site morbidity and was of the right anatomical size. Deformities were corrected using hinges or olive wires. One of the greatest advantages of this method is the patient to be ambulatory and bear weight from the start. Ilizarov considers this as an essential principle of this method. Functional loading of the extremity helps prevent and treat the disuse osteoporosis and soft tissue dystrophy that many of these patients have or develop because of prolonged periods of non-weight bearing. Few studies 6,10,11,12 have reported $90-100 \%$ rate of union with average treatment period between 5 - 7.5 months. Other studies have reported success of $90-100 \%$ with an average treatment time of $8-10$ months. Our report is comparable to studies, which have reported union rate of $70-100 \%$ at an average treatment time of more than 10 months. ${ }^{13,14,15}$ We obtained a union rate of $83.33 \%$ primarily, $90 \%$ patients obtained union with additional protection and minor procedures like bone grafting improved the union rate to $93.33 \%$. Control of infection occurred in $88.46 \%$ of cases with minor infection in the remaining $11.54 \%$. Final limb length discrepancy averaged $1.03 \mathrm{~cm}$. Control of infection and correction of limb length was high with the Ilizarov fixator. Tucker et $\mathrm{l}^{14}$ had treated seven patients of tibial non-union. They got a union rate of $100 \%$ with an average fixator time of 11.5 months. This was similar to our study where we took 10.24 months in fixator for union, we got only $93.33 \%$ union rate. This may be because the sample size was large in our series. In our as well as in his series the problem was not at the distraction site, where regenerating bone has been dependable, but at the original non-union site, where the bone end was atrophic had plugged medullary canals. Dendron's et al 16 treated twenty eight tibias using the Ilizarov bone transport method. He obtained 100\% union rate, in mean duration of treatment of 10 months. We have opened the non-union site in all cases. He tried to obtain union by closed means, and they opened and bone grafted the docking site only if compression of the site failed to achieve union. Naggar et al ${ }^{15}$ reported the cases of ten patients with eleven defects with a mean size of $6.7 \mathrm{~cm}$. All the ten patients were infected pre-operatively and all of them resolved after Ilizarov bone transport treatment. Six of the eleven patients with bone transport had difficulty with healing of the docking site; three patients with non-union failing to heal and required bone grafting or debridement to achieve union. They got a union rate of $72.73 \%$ with an average duration of treatment of 16.5 months; our average duration of treatment time is 14.62 months.

Polyzois et al ${ }^{17}$ treated forty two patients with bone defects, mean defect was $6 \mathrm{cms}$. Mean duration of treatment was 10 months. Union was achieved in all cases. The final limb length discrepancy was $1.5 \mathrm{~cm}$, which was comparable with our series of $1.2 \mathrm{cms}$. Cattaneo ${ }^{9}$ et al treated 28 patients with infected non-union tibia; he got $100 \%$ union with an average time of treatment in the apparatus of 9 months. In our series, the average time in fixator was 10.24 months. Five of his 28 patients had mild intermittent drainage after achieving union. He has not used antibiotics in 21 of his patients. The remaining seven patients received antibiotics for 10 days, three of over twenty six patients showed drainage after achieving union. We have used antibiotics for all our infected cases. The study of Cattaneo supports the premise that the principle of distraction osteogenesis and functional stabilisation facilitates resolution of bone infection. The ability to circumferentially resect the infected non-viable cortical bone appears to significantly alter the requirement for prolonged intravenous antibiotic therapy. The introduction of viable bone fragments under stable condition, through internal bone transport or the compression and stabilisation of non-union sites appear to encourage the natural host mechanisms to eliminate infections. Dagher and Rouboz ${ }^{12}$ reported on nine patients with tibial defects, average $6.3 \mathrm{~cm}$, treated using Ilizarov tibial transport. Four patients were infected preoperatively, all nine healed with no residual infection with less than $1 \mathrm{~cm}$ of limb length discrepancy. Schwartsman ${ }^{11}$ et al 22 studied 14 cases of tibial non-union treated with Ilizarov method. His overall union rate was 93\% with average duration of treatment being 5.8 months. The most common complication in their series was superficial pin tract infection. We also had similar problems. Another problem they encountered was acceptance of apparatus. We did not have any such problems. Green ${ }^{18}$ has done a comparative study of bone grafting and bone transport for segmental skeletal defects. In his bone transport group he got union in $94.12 \%$ with an average fixator time of 9.6 months. His results were comparable to our results. Cierny ${ }^{13}$ and Zorn ${ }^{13}$ compared twenty one patients with segmental tibial defects treated with bone transport using the Ilizarov apparatus with twenty three patients with tibial bone defects treated with massive cancellous bone grafts and soft tissue transfer. Their union rate was 95\%. In many 
studies, $17,11,19,20,18,21$ patients could weight bear in the immediate post-operative period. In this study, the patients found it difficult to be fully bear the weight without support. $85 \%$ remained partial weight bearing during most of the time in the fixator and graduated to full weight bearing without support only towards the completion of treatment. This may account for the major difference in treatment time shown by few authors. ${ }^{22,23}$ Ilizarov believes that return of function and micromotion of the non-union site accounts for shorter period of union than other conventional methods.

\section{Comparison of Other Studies}

\begin{tabular}{|c|c|c|c|c|c|c|}
\hline $\begin{array}{l}\text { Sl. } \\
\text { No. }\end{array}$ & Author & $\begin{array}{c}\text { Treatment Time } \\
\text { (Months) }\end{array}$ & $\begin{array}{l}\text { Total } \\
\text { Cases }\end{array}$ & $\begin{array}{c}\text { Infected } \\
\text { Cases }\end{array}$ & $\begin{array}{c}\text { Union } \\
\text { Attained }\end{array}$ & $\begin{array}{c}\text { Infection } \\
\text { Eradicated }\end{array}$ \\
\hline 1 & Schwartsman 11 & 7.5 & 14 & $28.57 \%$ & $93 \%$ & $100 \%$ \\
\hline 2 & Dagher $^{12}$ & 7.7 & 9 & $44.44 \%$ & $100 \%$ & $100 \%$ \\
\hline 3 & Cattaneo $^{9}$ & 9 & 28 & $100 \%$ & $100 \%$ & $78.57 \%$ \\
\hline 4 & Green $^{20}$ & 9.6 & 17 & $52.94 \%$ & $94.12 \%$ & - \\
\hline 5 & Dendrinos ${ }^{16}$ & 10 & 28 & $75 \%$ & $100 \%$ & $100 \%$ \\
\hline 6 & Polyzois ${ }^{17}$ & 10 & 25 & $66.67 \%$ & $90.4 \%$ & $100 \%$ \\
\hline 7 & Tucker ${ }^{14}$ & 11.5 & 7 & $71.43 \%$ & $100 \%$ & $14.28 \%$ \\
\hline 8 & Naggar15 & 16.5 & 10 & $100 \%$ & $72.73 \%$ & $100 \%$ \\
\hline 9 & Cierny ${ }^{13}$ & 17 & 21 & $100 \%$ & $90 \%$ & $100 \%$ \\
\hline 10 & Present Study & 14.62 & 30 & $90 \%$ & $93.33 \%$ & $88 \%$ \\
\hline
\end{tabular}

\section{CONCLUSION}

The Ilizarov method offered many advantages over traditional techniques of treatment of tibial non-union, especially in the presence of infection. It is a comprehensive method that addresses management of the bone defect, soft tissue loss and infection deformity and limb length discrepancy simultaneously. Control of infection and correction of limb length discrepancy can be more reliably achieved. In view of the complications and prolonged treatment duration, patients should be selected carefully and counselled regarding the same.

\section{REFERENCES}

1. Cabanela ME. Open cancellous bone grafting of infected bone defects. Ortho Clin North Am 1984;15(3):427-40.

2. De Oliveira JC. Bone grafts and chronic osteornyelitis. J Bone Joint Surg Br 1971;53(4):672-83.

3. Paterson D. Leg lengthening procedures. A historical review. Clin Orthop Relat Res 1990;(250):27-33.

4. Canale ST. Campbell's operative orthopaedics. $9^{\text {th }}$ edn. Elsevier 2017.

5. Nepola JV. External fixation. In: Rockwood CA, Green DP. eds. Fractures in adults. $4^{\text {th }}$ edn. 1996:229.

6. Clancey GJ, Winquist RA, Hansen ST. Non-union of' tibia treated with Kuntscher intrameduallary nailing. Clin Orthop Relat Res 1982;167:191-6.

7. Ellis $\mathrm{H}$. The speed of healing after fracture of the tibital shaft. J Bone Joint Surg 1958;40-B(1):42-6.

8. Nicoll EA. Fractures of the tibial shaft. A survey of 705 cases. J Bone Joint Surg Br 1964;46:373-87.

9. Cattaneo R, Catagni M, Johnson EE. The treatment of infected non union and segmental defects of the tibia by the methods of Ilizarov. Cli Ortho Rel Res 1992;280:14352.

10. DiPasquale D, Ochsner MG, Kelly AM, et al. The Ilizarov method for complex fracture nonunion. J Trauma 1994;37(4):629-34.

11. Schwartsman V, Choi SH, SH, Schwartsman R. Tibial non unions. Treatment tactics with the llizarov method. Ortho Clin North Am 1990;21(4):639-53.
12. Dagher F, Roukoz S. Compound tibial fractures with bone loss treated by llizarov technique. J Bone Joint Surg 1991;73(2):316-21.

13. Cierny G, Zorn KE. Segmental tibial defects. Comparing conventional and llizarov methodologies. Clin Ortho Relat Res 1994;301:118-23.

14. Tucker HL, Kendra JC, Kinnebrew TE. Tibial defects. Reconstruction using the method of llizarov as an alternative. Orthop Clin North Am 1990;21(4):629-37.

15. Naggar L, Chevalley F, Blanc CH, et al. Treatment of large bone defect with the llizarov technique. J Trauma 1993;34(3):390-3.

16. Dendrinos GK, Kontos S, Lyritsis E. Use of llizarov technique for treatment of non union of the tibia associated with infection. J Bone Joint Surg 1995;77(6):835-46.

17. Polyzois D, Papachristou G, Kotsiopoulos K, et al. Treatment of tiblal and femoral bone loss by distraction osteogenesis. Experience in 28 infected and 14 clean cases. Acta Orthop Scand Suppl 1997;275:84-8.

18. Green SA. Skeletal defects. A comparison of bone grafting and bone transport for segmental skeletal defects. Clin Orthop Relat Res 1994;301:111-7.

19. Sharma RK, Jayaswal A, Mathus V, et al. Bone transportation in the management of bone defects. Ind J Ortho 1993;27(2):112.

20. Bagnoli G. Model frames. In: Bagnoli. Edr. The llizarov method. BC Decker 1990:49.

21. Garcia-Cimbrelo E, Olsen B, Ruiz-Yague M, et al. Llizarov technique- results and difficulties. Clin Orthop Relat Res 1992;283:116-23.

22. Catagni MA, Guerreschi F, Holman JA, et al. Distraction osteogenesis in the treatment of stiff hypertrophic non unions using the llizarov apparatus. Clin Orthop Relat Res 1994;301:159-63.

23. Kulkarni GS. Text book of orthopaedics and trauma. $1^{\text {st }}$ edn. New Delhi: Jaypee Brothers 1999:1545. 